\section{Lesiones cutáneas como manifestación de una histoplasmosis diseminada en un hospital del Perú}

\author{
W. Samir Cubas, Gerardo Jiménez y Juan Vega
}

\section{Skin lesions of a disseminated histoplasmosis in Peru}

The dermatological manifestations of disseminated histoplasmosis present in about $17 \%$ of the cases, is a challenge for its diagnosis. We report the case of a patient from the northern coast of Peru, who presented diffuse dermal lesions, erythema-violaceous nodules, and ulcers histopathologically compatible with the infection of the genus Histoplasma var. capsulatum

Key words: Mycosis; skin diseases; histoplasmosis.

Palabras clave: Micosis; enfermedades cutáneas; histoplasmosis.

\section{Introducción}

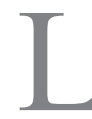

a histoplasmosis clásica o americana es una infección micótica granulomatosa sistémica de distribución mundial causada por el hongo dimórfico y geofílico denominado Histoplasma var. capsulatum ${ }^{1}$. Es endémico de zonas tropicales; en el Perú actualmente se ha comunicado una elevada incidencia en los departamentos de Huánuco (Cueva de Las Lechuzas), Loreto y San Martín ${ }^{2,3}$. La infección se adquiere por inhalación de las microconidias encontradas en suelos húmedos contaminados con heces de aves y murciélagos, alcanzan el pulmón y luego pueden diseminarse por vía sistémica ${ }^{4}$. Las manifestaciones dermatológicas son muy variadas, pudiendo presentarse lesiones de tipo papular eritematoso, nodular necrótico o hiperqueratósico, nodular eritemo-violáceo, foliculitis, pústulas, úlceras acneiformes o chancriformes, placas vegetantes y úlceras crónicas $^{5,6}$.

\section{Caso clínico}

Varón de 61 años de edad, proveniente de la costa norte del Perú, consultó por un cuadro de cinco meses de evolución de lesiones en la piel de tipo papular, no pruriginosas, en el hélix del pabellón auricular izquierdo y en la cara externa de los tobillos de ambas extremidades inferiores. Dichas lesiones mantuvieron un patrón de crecimiento lento y progresivo, que evolucionaron a nódulos de contenido líquido, coloración eritemo-violácea y de consistencia blanda. Algunos se erosionaron y otras se ulceraron presentando una secreción crónica sero-amarillenta, sin llegar a la cicatrización. Las lesiones se diseminaron en forma ascendente hasta

\footnotetext{
Hospital Regional Docente "Las Mercedes" Chiclayo, Perú (WSC, GJ, JV).

Recibido: 20 de marzo de 2017 / Aceptado: 29 de septiembre de 2017

Correspondencia a:

W. Samir Cubas Llalle

samir_24_10@hotmail.com
}

afectar toda la extensión de los miembros inferiores y el tronco. El paciente fue evaluado por el Área de Infecto-dermatología del Hospital Regional Docente "Las Mercedes" de Perú, evidenciándose unas lesiones nodulares eritemo-violáceas erosivas y algunas ulceradas de aspecto chancriforme de aproximadamente $3 \mathrm{~cm}$ de diámetro, de distribución difusa y no confluyente en las extremidades inferiores y tronco (Figura 1). Algunas de las lesiones eran de consistencia dura, dolorosas, mientras que las ulceradas presentaban bordes eritematosos, irregulares con secreción seroamarillenta, sin olor. Los exámenes complementarios de imagenología y laboratorio no presentaron hallazgos contributorios, incluyendo una radiografía de tórax normal y una serología para VIH negativa. Ante el problema diagnóstico se planteó el estudio histopatológico de las lesiones cutáneas, donde se concluyó la presencia de un infiltrado inflamatorio granulomatoso de la dermis de tipo linfoplasmocitario con presencia de células gigantes multinucleadas y numerosos microorganismos intracelulares morfológicamente compatibles con el género Histoplasma (Figura 2). Al reinterrogar al paciente, éste refirió que hacía cinco meses atrás había ingresado a un ambiente cerrado sin protección alguna, exponiéndose a numerosos residuos de excremento de aves y gran cantidad de polvo. El paciente recibió tratamiento con anfotericina $\mathrm{B}$ deoxicolato, hasta completar un gramo

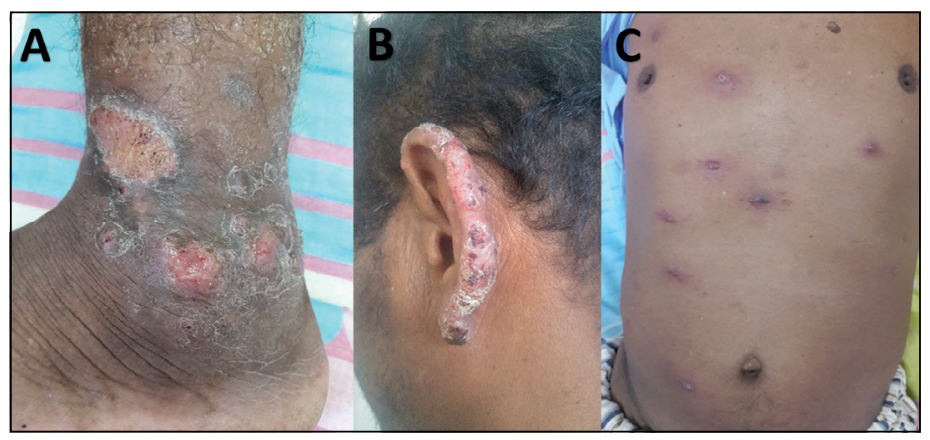

Figura 1. Histoplasmosis cutánea. A: Lesiones ulceradas en el tobillo de aspecto chancriforme con presencia de placas hiperqueratósicas de distribución perilesional. B: Lesiones sero-hemorrágicas con presencia de placas hiperqueratósicas en hélix de pabellón auricular izquierdo. C: Lesiones nodulares eritemo-violáceas en cara anterior del tronco.

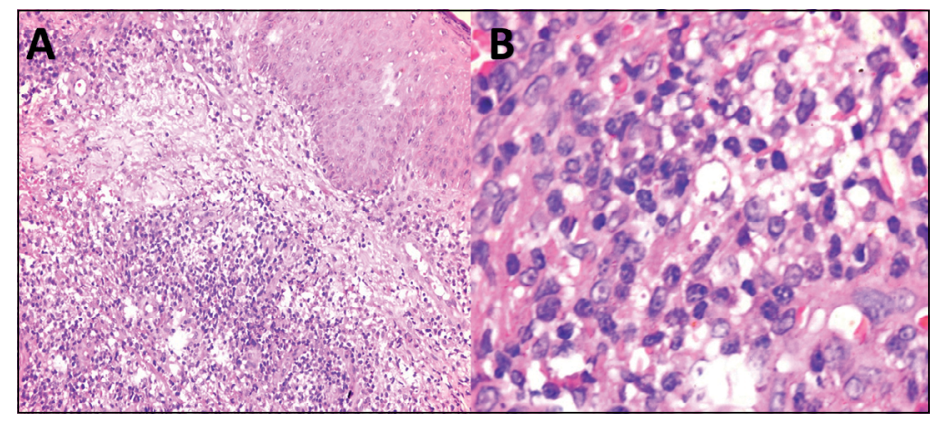

Figura 2. Estudio histopatológico de las lesiones cutáneas. A: Biopsia de lecho de úlcera (40x) con tinción hematoxilina-eosina. Infiltrado inflamatorio granulomatoso de tipo linfoplasmocitario con la presencia de numerosos microorganismos intracelulares morfológicamente compatibles con el género de Histoplasma var. capsulatum. B: Biopsia de lecho de úlcera (100x) con tinción hematoxilina-eosina. Macrófagos en cuyo citoplasma se identifican estructuras con una zona central oscura y pequeño halo periférico característico de la histoplasmosis. 


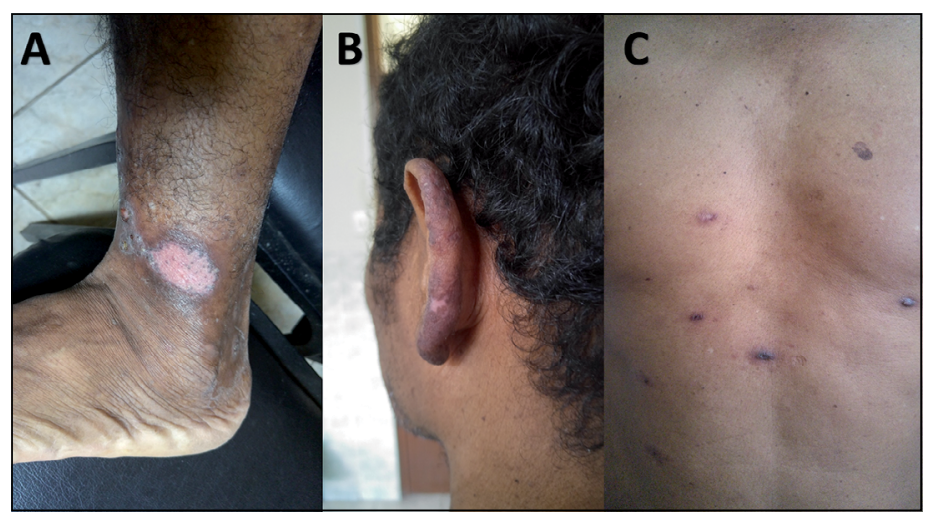

Figura 3. Histoplasmosis cutánea. Lesiones cutáneas en tobillo izquierdo, pabellón auricular y tronco anterior en proceso de cicatrización luego del tratamiento con anfotericina B-deoxicolato (A-B-C).

de dosis acumulada, evidenciándose mejoría clínica en el transcurso de su estancia hospitalaria (Figura 3). Posteriormente fue dado de alta con itraconazol, con controles clínicos periódicos y con el plan de completar terapia por al menos 12 meses.

\section{Discusión}

Las manifestaciones dermatológicas de la histoplasmosis diseminada representan $17 \%$ de los casos, casi siempre asociadas con algún grado de inmunodeficiencia en el hospedero ${ }^{7}$. Estas dermatosis se clasifican en dos grupos, independiente de si los pacientes tienen o no infección por VIH. Un primer grupo incluye las causadas por la presencia del hongo en la piel y el segundo se caracteriza por las reacciones cutáneas atribuibles a la infección micótica sistémica ${ }^{8,9}$. La diversidad de las lesiones dermatológicas ocasionadas por el género Histoplasma no son patognomónicas, ni permiten establecer un diagnóstico de certeza. Para algunos autores, esto se debe a la expresión morfológica heterogénea de la infección de la piel durante la fungemia, y que requieren el uso de métodos diagnósticos auxiliares como es el caso de la histopatología ${ }^{6}$. La histoplasmosis cursa con un amplio espectro de manifestaciones clínicas. Con menos frecuencia se presenta como formas diseminadas con afectación de uno o múltiples órganos, frecuentemente con características clínicas atípicas y que representan en su totalidad un reto médico para su diagnóstico ${ }^{1,10}$.

\section{Referencias bibliográficas}

1.- Contreras K, García P, Pinto J, Rodríguez P, González C, Vargas Brochero M J. Histoplasmosis diseminada y síndrome hemofagocítico en trasplante renal. Rev Colomb Nefrol 2017; 4: 93-8.

2.- Inocente A, Aguirre J, Torres R, Sifuentes Y, Salas E. Histoplasmoma ileal en un paciente con virus de inmunodeficiencia humana. Acta Méd Peruana 2012; 29: 194-6.

3.- Sánchez-Saldaña L, Galarza C, Cortéz-Franco F. Infecciones micóticas sistémicas o profundas: histoplasmosis. Dermatol Perú 2010; 20: $139-52$.

4.- Gill D, Dean R, Virk J, Lyons M, Hess M. Unusual presentation of disseminated histoplasmosis. Am J Emerg Med 2017; 35: 668e3-668e4.

5.- Sacoor M F. Disseminated cutaneous histoplasmosis with laryngeal involvement in a setting of immune reconstitution inflammatory syndrome. S Afr J HIV Med 2017; 18: a693.

6.- Carrasco-Zuber J, Navarrete-Dechent C, Bonifaz A, Fich F, Vial-Letelier $\mathrm{V}$, Berroeta-Mauriziano D. Afectación cutánea en las micosis profundas: una revisión de la literatura. Parte 2. Micosis sistémicas. Actas DermoSifiliográficas 2016; 107: 816-22.

7.- Kauffman CA. Treatment of the midwestern endemic mycoses, blastomycosis and histoplasmosis. Curr Fungal Infect Rep 2017: 1-8.

8.- Rodríguez G, Motta A, Ordóñez N. Estudio histopatológico de 19 biopsias cutáneas de pacientes con sida e histoplasmosis diseminada. Biomédica 2001; 21: 107-15.

9.- Orozco-Topete M L, Reyes E. Histoplamosis cutánea en nueve pacientes con SIDA. Rev Invest Clin 1998; 50: 52-8.

10.- Alcántara Figueroa C, Sánchez Cerna V. Histoplasmosis del colon y recto en un paciente de Perú. Rev Gastroenterol Peru 2016; 36: 365-8. 